\title{
Relationship between prehypertension and chronic kidney disease in middle-aged people in Korea: the Korean genome and epidemiology study
}

Min-Ju Kim, Nam-Kyoo Lim and Hyun-Young Park

\begin{abstract}
Background: Elevated blood pressure (BP) is a major risk factor for the progression of chronic kidney disease (CKD). However, little is known about the influence of prehypertension on CKD. In this study, we investigated the relationship between prehypertension and CKD in a middle-aged Korean population. Furthermore, we prospectively evaluated the effect of active BP control on deterioration of kidney function during the two-year follow-up.

Methods: The Korean Genome and Epidemiology Study is a community-based prospective cohort study started in 2001, with a follow-up survey conducted every two years. A total of 9509 participants aged 40-69 years were included in a baseline study. BP was classified according to the Seventh Report of the Joint National Committee on High BP (JNC-7) categories and CKD was defined as the presence of proteinuria or eGFR $<60 \mathrm{~mL} / \mathrm{min} / 1.73 \mathrm{~m}^{2}$. A multivariable logistic regression model was used to identify associations between BP and CKD.

Results: The overall prevalence of CKD was 13.2\%, and significantly increased with BP level. The multivariable-adjusted odds ratio of CKD was 1.59 for prehypertension and 2.27 for hypertension, compared with a normal BP. At the two-year follow-up, among the participants with prehypertension, subjects whose BP was poorly controlled had a significantly higher risk of eGFR drop (OR, 1.37; 95\% Cl, 1.13-1.67), as compared to controls. The prevalence of eGFR drop was 57.8\% in the controlled BP group and 66.0\% in the poorly-controlled BP group.

Conclusions: Prehypertension, as well as hypertension, is significantly associated with CKD among middle-aged Koreans. Our results indicate that active control of the blood-pressure of prehypertensive individuals is needed to prevent deterioration of kidney function.
\end{abstract}

Keywords: Blood pressure, Chronic kidney disease, Prehypertension, Estimated glomerular filtration rate

\section{Background}

Chronic kidney disease (CKD) is associated with allcause mortality, progression to end-stage renal disease (ESRD), cardiovascular disease (CVD), and many chronic diseases, such as diabetes [1-5].

The prevalence of CKD in the United States has increased from $10.0 \%$ in $1988-1994$ to $13.1 \%$ in 1999 2004 [6]. In a population-based cross-sectional epidemiologic study in Korea, the prevalences of CKD and decreased kidney function were $13.7 \%$ and $5.0 \%$, respectively [7].

\footnotetext{
* Correspondence: mdhypark@gmail.com

Division of Cardiovascular and Rare Diseases, Center for Biomedical Science, National Institute of Health, Chungbuk, South Korea
}

According to the Kidney Disease Outcomes Quality Initiative (KDOQI) guidelines, CKD is defined as a marker of kidney damage and/or glomerular filtration rate (GFR) < $60 \mathrm{~mL} / \mathrm{min} / 1.73 \mathrm{~m}^{2}$ for at least three months; in addition, GFR is usually estimated from serum creatinine ( $\mathrm{Scr}$ ) values alone or prediction equations that take into account the Scr, age, gender and race [8]. Therefore, use of estimated glomerular filtration rate (eGFR) is commonly recommended to screen patients with CKD $[8,9]$. Furthermore, management of high risk patients who have hypertension and diabetes is particularly important $[8,9]$.

Elevated blood pressure (BP) is closely associated with $\mathrm{CKD}$ progression, and lowering of BP may slow down 
GFR decline [10,11]. A number of studies have reported that hypertension is involved in CKD, emphasizing the importance of BP control in improving kidney function [12-14]. Both Kidney Early Evaluation Program (KEEP) and National Health and Nutrition Examination Survey (NHANES) data showed a strong association between hypertension and kidney disease [14]. The Seventh Report of the Joint National Committee on High BP (JNC-7) suggests controlling BP at $<130 / 80 \mathrm{mmHg}$ in patients with CKD [15]. Recently, a population-based, cross-sectional study from Singapore demonstrated that $\mathrm{BP}$ is independently associated with CKD, and that poorly controlled hypertension has a significantly stronger relationship with kidney damage than treated, controlled hypertension [16]. In addition, Higashikuni et al. found that a BP above $110 / 75 \mathrm{mmHg}$ was significantly associated with albuminuria in a Japanese population without hypertension, but not with eGFR [17].

Although several studies have suggested that hypertension is a significant risk factor for CKD, little is known of its association with prehypertension and CKD. In this study, we investigated the relationship between prehypertension and CKD in a middle-aged Korean population. To determine the effect of BP control on deterioration of kidney function, we prospectively evaluated eGFR drop according to the change of BP during the two-year follow-up.

\section{Methods}

\section{Study participants}

The Korean Genome and Epidemiology Study is a population-based prospective cohort study for the purpose of investigating the prevalence and risk factors of chronic disease in Korea, with the support of the Korean National Institute of Health. The baseline survey was performed in 2001-2002 on 10038 participants aged over 40 years and follow-up examinations were conducted every two year. Specimens were collected from the groups of residents representing each local population in a rural and an urban area (Anseong and Ansan, respectively). We obtained baseline and 2-year follow-up data from the Center for Genome Science in the National Institute of Health, Korea. The details of the present cohort have been described elsewhere $[18,19]$. Of 10038 participants enrolled in a rural and an urban area (Anseong and Ansan, respectively), 10013 subjects between the ages of 40 and 69 were selected to participate in a baseline survey. After exclusion of six subjects with missing Scr values, 496 who had incomplete data and two with CKD stage 5 (eGFR $<15 \mathrm{~mL} / \mathrm{min} / 1.73 \mathrm{~m}^{2}$ ), 9509 participants were included for baseline study. At the 2-year follow-up examination, 8603 participants were enrolled in this study after exclusion of 92 death and 814 lost to follow-up. Of those, 8149 people with complete data were selected to participate in a follow-up survey. We excluded 2108 and two participants with missing Scr and BP values, respectively. Thus, 6039 subjects were included in the present study (Figure 1). Of these, 2367 with prehypertension at baseline were selected and their BP change during two-year follow-up determined. Subjects were divided into controlled and poorlycontrolled groups. The study protocol was approved by the Institutional Review Board of the Korea Centers for Disease Control and Prevention. Written informed consent was obtained from all study participants.

\section{Measurement of BP}

Measurement of BP was performed after a 5 min period of rest using a mercury sphygmomanometer, and two BP readings were taken from both arms at $30 \mathrm{~s}$ intervals. The average systolic and diastolic BP values of two measurements taken in a sitting position were recorded.

BP was classified according to the Seventh Report of the Joint National Committee on High BP (JNC-7) categories [15]; normal BP $(<120 \mathrm{~mm} \mathrm{Hg}$ systolic and $<80 \mathrm{~mm} \mathrm{Hg}$ diastolic); prehypertension (120 to $139 \mathrm{~mm}$ $\mathrm{Hg}$ systolic or 80 to $89 \mathrm{~mm} \mathrm{Hg}$ diastolic); hypertension ( $\geq 140 \mathrm{~mm} \mathrm{Hg}$ systolic or $\geq 90 \mathrm{~mm} \mathrm{Hg}$ diastolic systolic or use of antihypertensive medication).

Controlled BP was defined as participants who maintained a normal BP, and poorly-controlled BP as those with prehypertension or hypertension at the two-year follow-up.

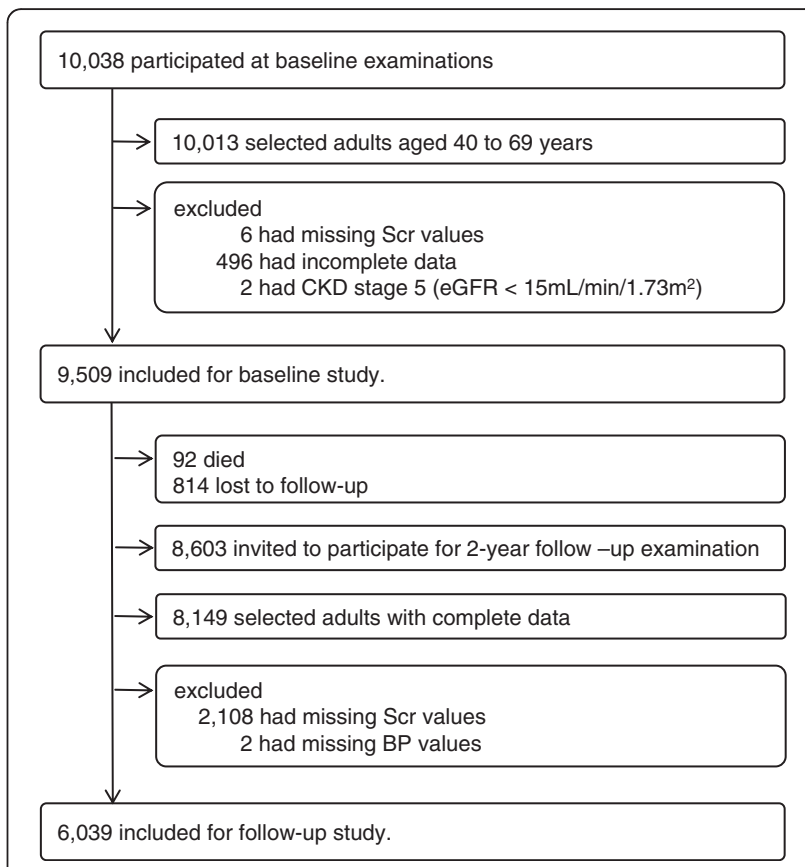

Figure 1 Study participants at baseline and follow-up examinations. 


\section{Other measurements}

Demographic, medical and behavioral characteristics were obtained using a standardized questionnaire, and included age, sex, cigarette smoking and alcohol intake.

Body weight and height were measured to the nearest $0.1 \mathrm{~kg}$ or $0.1 \mathrm{~cm}$ and body mass index (BMI) was calculated as body weight $(\mathrm{kg})$ divided by height (meters) squared. Waist circumference (WC) was measured at the midpoint between the ribs and the iliac crest in the standing position.

Blood samples were collected after an 8-14 h fast. Fasting plasma glucose (FPG), total cholesterol (TC), triglyceride (TG), high-density lipoprotein cholesterol (HDL-C) and Scr levels were measured enzymatically, and low-density lipoprotein cholesterol (LDL-C) levels were estimated by the Friedwald formula [20]. Proteinuria tested by the dipstick method was defined as $1+$ or more.

\section{Definitions of CKD and diabetes mellitus (DM)}

According to the Kidney Disease Outcomes Quality Initiative (KDOQI) guidelines, CKD is defined as a marker of kidney damage and/or GFR $<60 \mathrm{~mL} / \mathrm{min} / 1.73 \mathrm{~m}^{2}$ for at least three months [8]. We defined CKD as the presence of proteinuria or eGFR $<60 \mathrm{~mL} / \mathrm{min} / 1.73 \mathrm{~m}^{2}$. CKD stages were classified as follows: stage 1 , proteinuria $(\geq 1+)$ with eGFR $\geq 90 \mathrm{~mL} / \mathrm{min} / 1.73 \mathrm{~m}^{2}$; stage 2 , proteinuria $(\geq 1+)$ with eGFR $60-89 \mathrm{~mL} / \mathrm{min} / 1.73 \mathrm{~m}^{2}$; stage 3 , eGFR $30-59 \mathrm{~mL} / \mathrm{min} / 1.73 \mathrm{~m}^{2}$, and stage 4 , eGFR $15-29 \mathrm{~mL} / \mathrm{min} / 1.73 \mathrm{~m}^{2}$. eGFR was calculated using the following equation [8]: eGFR $=186.3 \times(\mathrm{Scr}$ in $\mathrm{mg} / \mathrm{dL})^{-1.154} \times \mathrm{Age}^{-0.203} \times(0.742$ if female $)$. Changes in kidney function were evaluated using baseline and twoyear follow-up eGFR values. eGFR drop denotes a decline in eGFR between baseline and the two-year follow-up.

DM was diagnosed as an FPG $\geq 126 \mathrm{mg} / \mathrm{dl}$ or 2 -h postchallenge plasma glucose ( $2 \mathrm{~h} \mathrm{PG}) \geq 200 \mathrm{mg} / \mathrm{dl}$ or hemoglobin $\mathrm{A}_{1 \mathrm{C}}\left(\mathrm{HbA}_{1 \mathrm{C}}\right) \geq 6.5 \%$, or use of oral hypoglycemic agents using the 2010 criteria of the American Diabetes Association (ADA) [21].

\section{Statistical analysis}

The baseline characteristics of subjects were expressed as means and standard deviations for continuous variables. Statistical differences between groups were performed by one-way analysis of variance (ANOVA) for continuous variables and the chi-square test for categorical variables. A multivariable logistic regression model was used to identify associations between BP and CKD. $\mathrm{C}$-statistics were calculated to compare the ability of different logistic models to discriminate participants with and without CKD. After two-year follow-up, the odds ratio of eGFR drop according to $\mathrm{BP}$ change was calculated by multivariable logistic regression analysis. Values of $P<0.05$ were considered to be statistically significant. The data were analyzed using the SAS software (version 9.2; SAS Institute, Cary, North Carolina).

\section{Results}

\section{Baseline characteristics}

The baseline characteristics of the participants according to BP category are shown in Table 1 . Of 9509 participants, there were 3792 normotensive (39.9\%), 3873 prehypertensive (40.7\%) and 1844 hypertensive (19.4\%) subjects. The mean age of subjects was 52 years, $47.9 \%$ were male and their mean BMI was $24.6 \mathrm{~kg} / \mathrm{m}^{2}$. The BMI, WC, FPG, TC, LDL-C and TG levels were increased when BP level was high. Hypertensive participants were more likely to have a history of DM (11.5\% in the prehypertension group and $19.3 \%$ in the hypertension group). Of all subjects, $25.8 \%$ were current smokers and $47.7 \%$ were alcohol drinkers. The mean GFR estimated using the Modification of Diet in Renal Disease (MDRD) equation was $74.0 \pm 14.0 \mathrm{~mL} / \mathrm{min} / 1.73 \mathrm{~m}^{2}$, and was lowest in the hypertension group. The proportion of individuals with eGFR $<60 \mathrm{~mL} / \mathrm{min} / 1.73 \mathrm{~m}^{2}$ in the normal BP, prehypertension and hypertension groups were $5.6 \%, 11.4 \%$ and $23.3 \%$, respectively. Two-hundred and seventeen subjects $(2.3 \%)$ had proteinuria $(\geq 1+)$, which was more prevalent in subjects with hypertension than in those with a normal BP.

\section{Prevalence of CKD}

The overall prevalence of CKD stages 1 to 4 was $13.2 \%$, and increased significantly with BP level $(P$ trend $<0.001)$. CKD prevalence according to stage was $13.8 \%$ in stages 1 and 2, 85.4\% in stage 3, and $0.8 \%$ in stage 4 . Participants with hypertension showed the highest CKD prevalence. There was a gender difference in CKD prevalence (3.5\% in males and $22.2 \%$ in females). Females had a higher prevalence of CKD in all categories (Table 2).

\section{Results of multivariable logistic regression analysis of CKD}

The results of multivariable logistic regression analysis of CKD according to BP category are presented in Table 3. The multivariable-adjusted odds ratio (OR) of CKD was 1.59 (95\% CI, 1.29-1.95) in subjects with prehypertension, and 2.27 (95\% CI, 1.80-2.86) in subjects with hypertension, compared with those with a normal BP. Both prehypertension and hypertension showed significant positive associations with CKD after adjustment for age, sex, BMI, FPG, TC, TG, HDL-C, WC, and smoking and alcohol drinking habits. The c-statistic was 0.90 in the multivariable-adjusted Model 3, which had a 
Table 1 Mean values of baseline characteristics according to BP category

\begin{tabular}{|c|c|c|c|c|c|}
\hline \multirow[t]{2}{*}{ Variables } & \multirow[t]{2}{*}{ Total $(n=9509)$} & \multicolumn{3}{|c|}{ BP category } & \multirow[t]{2}{*}{$P$-value } \\
\hline & & $\begin{array}{l}\text { Normal BP } \\
(n=3792)\end{array}$ & $\begin{array}{c}\text { Prehypertension } \\
(n=3873)\end{array}$ & $\begin{array}{c}\text { Hypertension } \\
(n=1844)\end{array}$ & \\
\hline Age (years) & $52.1 \pm 8.9$ & $49.0 \pm 7.9$ & $52.8 \pm 8.8$ & $56.9 \pm 8.2$ & $<0.001$ \\
\hline $40-49$ & 4557 (47.9) & $2393(63.1)$ & $1730(44.7)$ & $434(23.5)$ & \\
\hline $50-59$ & $2481(26.1)$ & $847(22.3)$ & $1042(26.9)$ & $592(32.1)$ & \\
\hline 60-69 & $2471(26.0)$ & $552(14.6)$ & 1101 (28.4) & $818(44.4)$ & \\
\hline Gender, male & $4566(48.0)$ & $1594(42.0)$ & $2164(55.9)$ & $808(43.8)$ & $<0.001$ \\
\hline BMI $\left(\mathrm{kg} / \mathrm{m}^{2}\right)$ & $24.6 \pm 3.1$ & $23.8 \pm 2.9$ & $24.7 \pm 3.1$ & $25.8 \pm 3.3$ & $<0.001$ \\
\hline WC (cm) & $82.6 \pm 8.8$ & $79.5 \pm 8.2$ & $83.6 \pm 8.4$ & $86.7 \pm 8.5$ & $<0.001$ \\
\hline Diabetes & $1069(11.2)$ & $267(7.0)$ & $447(11.5)$ & $355(19.3)$ & $<0.001$ \\
\hline Current smokers & 2455 (25.8) & $960(25.3)$ & 1125 (29.1) & $370(20.1)$ & $<0.001$ \\
\hline Alcohol drinkers & $4535(47.7)$ & $1715(45.2)$ & 2016 (52.1) & $804(43.6)$ & $<0.001$ \\
\hline SBP $(\mathrm{mmHg})$ & $121.3 \pm 18.4$ & $105.5 \pm 8.2$ & $125.9 \pm 9.9$ & $144.4 \pm 17.6$ & $<0.001$ \\
\hline $\mathrm{DBP}(\mathrm{mmHg})$ & $80.3 \pm 11.4$ & $70.2 \pm 6.0$ & $84.2 \pm 6.5$ & $92.7 \pm 10.7$ & $<0.001$ \\
\hline FPG (mg/dL) & $87.3 \pm 21.4$ & $84.7 \pm 19.1$ & $88.1 \pm 21.3$ & $91.3 \pm 25.3$ & $<0.001$ \\
\hline $\mathrm{TC}(\mathrm{mg} / \mathrm{dL})$ & $191.5 \pm 35.7$ & $186.6 \pm 34.1$ & $193.2 \pm 35.7$ & $198.3 \pm 37.3$ & $<0.001$ \\
\hline $\mathrm{HDL}-\mathrm{C}(\mathrm{mg} / \mathrm{dL})$ & $44.8 \pm 10.1$ & $45.3 \pm 9.9$ & $44.7 \pm 10.1$ & $43.9 \pm 10.3$ & $<0.001$ \\
\hline LDL-C (mg/dL) & $114.6 \pm 33.6$ & $113.2 \pm 31.5$ & $114.6 \pm 34.2$ & $117.4 \pm 36.0$ & $<0.001$ \\
\hline $\mathrm{TG}(\mathrm{mg} / \mathrm{dL})$ & $161.0 \pm 103.0$ & $140.5 \pm 89.9$ & $169.9 \pm 109.9$ & $184.7 \pm 105.3$ & $<0.001$ \\
\hline $\mathrm{Scr}(\mathrm{mg} / \mathrm{dL})$ & $1.00 \pm 0.10$ & $0.99 \pm 0.10$ & $1.00 \pm 0.11$ & $1.00 \pm 0.20$ & $<0.001$ \\
\hline eGFR (mL/min/1.73 $\left.\mathrm{m}^{2}\right)$ & $74.0 \pm 14.0$ & $73.9 \pm 14.0$ & $75.2 \pm 13.8$ & $71.6 \pm 13.9$ & $<0.001$ \\
\hline$\geq 90$ & $523(5.5)$ & $219(5.8)$ & $210(5.4)$ & $94(5.1)$ & \\
\hline $60-89$ & $7903(83.1)$ & $3361(88.6)$ & $3222(83.2)$ & $1320(71.6)$ & \\
\hline $30-59$ & $1073(11.3)$ & $212(5.6)$ & $439(11.3)$ & $422(22.9)$ & \\
\hline $15-29$ & $10(0.1)$ & $0(0.0)$ & $2(0.1)$ & $8(0.4)$ & \\
\hline Proteinuria $(\geq 1+)$ & $217(2.3)$ & $45(1.2)$ & $92(2.4)$ & $79(4.3)$ & $<0.001$ \\
\hline
\end{tabular}

Data are expressed as mean \pm SD or percentage. One-way ANOVA was used for continuous variables.

BP categories were defined as follows: Normal BP, SBP $<120 \mathrm{mmHg}$ and DBP $<80 \mathrm{mmHg}$; Prehypertension, SBP $120-139 \mathrm{mmHg}$ or DBP $80-89 \mathrm{mmHg}$; Hypertension, SBP $\geq 140 \mathrm{mmHg}$ or $\mathrm{DBP} \geq 90 \mathrm{mmHg}$ or use of antihypertensive medications.

better discrimination capability than the unadjusted model (c-statistic of 0.66).

\section{Odds ratio for eGFR drop during the two-year follow-up}

Table 4 shows the odds ratio (OR) for eGFR drop according to the change of BP during the two-year follow-up. Among all subjects included in the follow-up study, 3133 had controlled BP (normal BP at two-year follow-up) and 2906 had poorly-controlled BP (prehypertension or hypertension at two-year follow-up). A total of 1644 (52.5\%) subjects in the controlled and 1827 (62.9\%) in the poorly-controlled BP groups experienced a drop in eGFR. According to the multivariable logistic regression analysis, subjects whose BP was not controlled had a significantly higher risk of eGFR drop (OR, 1.22; 95\% CI, 1.08-1.38) when the controlled BP group was used as a reference. Of 2367 subjects with prehypertension, 857 had controlled BP (normal BP at twoyear follow-up) and 1510 had poorly-controlled BP (prehypertension or hypertension at two-year follow-up). The prevalence of eGFR drop was $57.8 \%$ in the controlled BP group and $66.0 \%$ in the poorly-controlled BP group. Compared to subjects with controlled BP, the risk of eGFR drop increased by 1.37 (95\% CI, 1.13-1.67) times for those with poorly-controlled $\mathrm{BP}$ after adjustment for age, sex, BMI, FPG, TC, TG, HDL-C, WC, and smoking and alcohol drinking habits. The c-statistics in multivariable-adjusted Model 3 showed the best discrimination capability.

\section{Discussion}

The purpose of this study was to examine the relationship between BP and CKD in a middle-aged Korean population. We found a strong and independent association between prehypertension, as well as hypertension, and CKD. Our data also indicated that the risk of eGFR drop at the two-year follow-up was significantly greater 
Table 2 Prevalence of CKD according to BP category

\begin{tabular}{|c|c|c|c|c|c|}
\hline \multirow[t]{2}{*}{ Variables } & \multirow[t]{2}{*}{ Total } & \multicolumn{3}{|c|}{ BP category } & \multirow[t]{2}{*}{$P$-value } \\
\hline & & $\begin{array}{c}\text { Normal BP } \\
(n=3792)\end{array}$ & $\begin{array}{c}\text { Prehypertension } \\
(n=3873)\end{array}$ & $\begin{array}{c}\text { Hypertension } \\
(n=1844)\end{array}$ & \\
\hline \multicolumn{6}{|l|}{ All $(n=9509)$} \\
\hline No-CKD & 8252 (86.8) & 3541 (93.4) & 3357 (86.7) & $1354(73.4)$ & \multirow[t]{5}{*}{$<0.001$} \\
\hline All CKD & $1257(13.2)$ & 251 (6.6) & $516(13.3)$ & $490(26.6)$ & \\
\hline Stages 1 and 2 & $174(13.8)$ & 39 (15.5) & $75(14.5)$ & $60(12.2)$ & \\
\hline Stage 3 & $1073(85.4)$ & $212(84.5)$ & $439(85.1)$ & $422(86.1)$ & \\
\hline Stage 4 & $10(0.8)$ & $0(0.0)$ & $2(0.4)$ & $8(1.6)$ & \\
\hline \multicolumn{6}{|l|}{ Males $(n=4566)$} \\
\hline No-CKD & 4408 (96.5) & 1571 (98.6) & 2088 (96.5) & $749(92.7)$ & \multirow[t]{5}{*}{$<0.001$} \\
\hline All CKD & $158(3.5)$ & $23(1.4)$ & $76(3.5)$ & $59(7.3)$ & \\
\hline Stages 1 and 2 & $111(70.3)$ & $20(87.0)$ & $53(69.7)$ & $38(64.4)$ & \\
\hline Stage 3 & $44(27.8)$ & $3(13.0)$ & $23(30.3)$ & 18 (30.5) & \\
\hline Stage 4 & $3(1.9)$ & $0(0.0)$ & $0(0.0)$ & $3(5.1)$ & \\
\hline \multicolumn{6}{|l|}{ Females ( $n=4943$ ) } \\
\hline No-CKD & 3844 (77.8) & 1970 (89.6) & $1269(74.3)$ & $605(58.4)$ & \multirow[t]{5}{*}{$<0.001$} \\
\hline All CKD & $1099(22.2)$ & $228(10.4)$ & $440(25.8)$ & 431 (41.6) & \\
\hline Stages 1 and 2 & $63(5.7)$ & $19(8.3)$ & $22(5.0)$ & $22(5.1)$ & \\
\hline Stage 3 & 1029 (93.6) & $209(91.7)$ & $416(94.5)$ & $404(93.7)$ & \\
\hline Stage 4 & $7(0.6)$ & $0(0.0)$ & $2(0.5)$ & $5(1.2)$ & \\
\hline
\end{tabular}

Data are expressed as $n$ (\%) and tested by chi-square test at $P<0.05$.

CKD was defined as estimated glomerular filtration rate (eGFR) $<60 \mathrm{ml} / \mathrm{min}$ per $1.73 \mathrm{~m}^{2}$ and/or the presence of proteinuria ( $\geq 1+$ ).

when BP was poorly-controlled. The risk increased beginning with prehypertensive participants.

In this study of 9509 Koreans aged 40-69 years, the prevalence of CKD was $13.2 \%$, similar to the results of an epidemiologic study in urban Korea, which reported an overall CKD prevalence of $13.7 \%$ [7]. The prevalence of CKD was greater in females than in males $3.5 \%$ in males and $22.2 \%$ in females) as in other Korean population studies [22]. This discrepancy may be possibly explained by the increased filtration fraction in men, which may contribute to maintain the GFR [23,24].

In addition, results from NHANES 1999-2004 in the United States indicated that the prevalence of CKD stages 1 to 4 was $13.1 \%$ [6]. Among Australian adults aged 25 years or older, approximately $16 \%$ had at least one indicator of kidney damage [25]. The prevalence of CKD differs among ethnic groups, and the Asian population had a relatively high prevalence [26]. It is estimated that, in Japan, approximately $19 \%$ of the adult population has stages 3 to 5 CKD [27], and the prevalence of CKD in Beijing was $12.9 \%$ [28]. Furthermore, in the NHANES 1999-2006 in the US, $17.3 \%$ and $22.0 \%$ of those with prehypertension and undiagnosed hypertension, respectively, had CKD as determined by eGFR or albuminuria [29].

We used the MDRD equation to estimate GFR because it has been widely used in epidemiologic studies

Table 3 Unadjusted and multivariable-adjusted odds ratio (OR) and c statistics of CKD according to BP category

\begin{tabular}{lcccc}
\hline \multicolumn{1}{c}{ Variables } & \multicolumn{3}{c}{ CKD } \\
\cline { 2 - 5 } & $\begin{array}{c}\text { Unadjusted OR } \\
\mathbf{( 9 5 \% ~ C l )}\end{array}$ & $\begin{array}{c}\text { Model 1 OR } \\
\mathbf{( 9 5 \% ~ C l )}\end{array}$ & $\begin{array}{c}\text { Model 2 OR } \\
\mathbf{( 9 5 \% ~ C l )}\end{array}$ & $\begin{array}{c}\text { Model 3 OR } \\
\mathbf{( 9 5 \% ~ C l )}\end{array}$ \\
\hline Normal BP & 1.00 (reference) & 1.00 (reference) & 1.00 (reference) & $1.00($ reference) \\
Prehypertension & $2.17(1.85-2.54)^{*}$ & $1.69(1.38-2.06)^{*}$ & $1.68(1.37-2.06)^{*}$ & $2.59(1.29-1.95)^{*}$ \\
Hypertension & $5.11(4.33-6.02)^{*}$ & $2.52(2.02-3.13)^{*}$ & $2.49(1.99-3.12)^{*}$ & $2.27(1.80-2.86)^{*}$ \\
c-statistic & 0.66 & 0.89 & 0.89 & 0.90 \\
\hline
\end{tabular}

Model 1: adjusted for age and sex.

Model 2: adjusted for age, sex and BMI.

Model 3: adjusted for age, sex, BMI, FBG, TC, TG, HDL-C, WC, current smokers and alcohol drinkers.

${ }^{*} P<0.001$. 
Table 4 Unadjusted and multivariable-adjusted odds ratio (OR) for eGFR drop according to change in BP

\begin{tabular}{|c|c|c|c|c|c|c|}
\hline \multirow{2}{*}{$\begin{array}{l}\text { BP change } \\
\text { after } 2 \text { years }\end{array}$} & \multirow{2}{*}{$\begin{array}{l}\text { No. at } \\
\text { risk }\end{array}$} & \multirow{2}{*}{$\begin{array}{c}\text { No. with } \\
\text { eGFR drop (\%) }\end{array}$} & \multicolumn{4}{|c|}{ eGFR drop } \\
\hline & & & $\begin{array}{c}\text { Unadjusted OR } \\
(95 \% \mathrm{Cl})\end{array}$ & $\begin{array}{l}\text { Model } 1 \text { OR } \\
(95 \% \mathrm{Cl})\end{array}$ & $\begin{array}{l}\text { Model } 2 \text { OR } \\
(95 \% \mathrm{Cl})\end{array}$ & $\begin{array}{l}\text { Model } 3 \text { OR } \\
(95 \% \mathrm{Cl})\end{array}$ \\
\hline \multicolumn{7}{|l|}{ All } \\
\hline Controlled BP & 3133 & $1644(52.5)$ & 1.00 (reference) & 1.00 (reference) & 1.00 (reference) & 1.00 (reference) \\
\hline Poorly-controlled BP & 2906 & $1827(62.9)$ & $1.53(1.38-1.70)^{* *}$ & $1.31(1.16-1.47)^{* *}$ & $1.23(1.09-1.39)^{* *}$ & $1.22(1.08-1.38)^{*}$ \\
\hline c-statistic & & & 0.55 & 0.74 & 0.75 & 0.76 \\
\hline \multicolumn{7}{|l|}{ Prehypertension } \\
\hline Controlled BP & 857 & $495(57.8)$ & 1.00 (reference) & 1.00 (reference) & 1.00 (reference) & 1.00 (reference) \\
\hline Poorly-controlled BP & 1510 & $997(66.0)$ & $1.42(1.20-1.69)^{* *}$ & $1.39(1.15-1.69)^{* *}$ & $1.35(1.11-1.63)^{*}$ & $1.37(1.13-1.67)^{*}$ \\
\hline c-statistic & & & 0.54 & 0.74 & 0.75 & 0.76 \\
\hline \multicolumn{7}{|c|}{$\begin{array}{l}\text { a eGFR drop denotes the decline in eGFR between baseline and the two-year follow-up. } \\
\text { (Changes in eGFR }(\Delta)=\text { eGFR at two-year follow-up }- \text { eGFR at baseline). } \\
\text { bControlled BP was defined as participants who had a normal BP at the two-year follow-up. } \\
\text { 'Poorly-controlled BP was defined as participants who were prehypertensive or hypertensive at the two-year follow-up. } \\
\text { Model 1: adjusted for age and sex. } \\
\text { Model 2: adjusted for age, sex and BMI. } \\
\text { Model 3: adjusted for age, sex, BMI, FBG, TC, TG, HDL-C, WC, current smokers and alcohol drinkers. } \\
{ }^{*} P<0.01,{ }^{* *} P<0.001 \text {. }\end{array}$} \\
\hline
\end{tabular}

and clinical practice. When eGFR was calculated by the Chronic Kidney Disease Epidemiology Collaboration (CKD-EPI) equation [30], the mean eGFR and prevalence of CKD was similar to our results [see Additional file 1, Additional file 2]. In addition, when we applied the equations for Korean population [31], the mean eGFR differed from those by the MDRD equation and the prevalence of CKD was lower than in our results, especially in females [see Additional file 1, Additional file 3, Additional file 4]. However, the equations for Korean population may need to be evaluated its validity in a variety of population with larger sample size.

We found that CKD prevalence increased with BP level; normotensive subjects showed the lowest prevalence and hypertensive subjects the highest (6.6, 13.3 and $26.6 \%$ for normal BP, prehypertension and hypertension, respectively).

Hypertension is a well-known risk factor for CKD progression [12-14]. However, the influence of BP on CKD in the general population in Korea has not been thoroughly evaluated. In addition, whether prehypertension has an effect on CKD remains controversial. In this study, we focused particularly on the risk of CKD in prehypertensive subjects.

Several cohort studies provided strong epidemiologic evidence regarding the risk of ESRD across the BP categories. Our results were consistent with those of an earlier study, which reported that the risk of ESRD was increased even with normal but not optimal and highnormal levels, as well as hypertension [32,33]. In our data, a multiple logistic regression analysis indicated that prehypertensive and hypertensive participants had a $\sim 1.6$ and $\sim 2.3$ times increased risk of CKD. Moreover, studies from the Asia-Pacific region reported that high $\mathrm{BP}$ was the strongest risk factor ( $>80 \%$ greater) for renal death, indicating the importance of risk factors for CKD in Asia [34]. Recent studies of the combined effect of prehypertension and obesity on CKD risk showed that prehypertensive and obese subjects were at increased risk of CKD $[35,36]$.

Our follow-up results showed that subjects with poorly-controlled BP were more likely to have a decreased eGFR compared with those with controlled BP. The risk of eGFR drop was significantly increased among the poorly-controlled BP group in all, and prehypertensive participants (Table 4). These findings support the JNC-7 recommendation: a reduction in BP to $<130 /$ $80 \mathrm{mmHg}$ for CKD patients to prevent cardiovascular disease outcomes [15]. The MDRD trial demonstrated a beneficial effect of BP control on progression of chronic kidney disease; this may support our findings. In a longterm follow-up of participants with a moderately- to severely-decreased GFR, as compared to baseline, those with a reduced target BP had a delayed onset of kidney failure and the composite outcome, as compared with the usual-target group [37]. Also, effective control of BP using antihypertensive agents such as angiotensinconverting enzyme inhibitors (ACEI), reduced proteinuria and ameliorated GFR [38].

Interestingly, the risk of CKD significantly increased in prehypertensive subjects, and those with poorly controlled BP had a higher risk of eGFR drop at the twoyear follow-up. That is, the increased CKD risk begins at a near-normal BP; therefore, those individuals may be considered for active BP control to reduce the burden of kidney disease. 
The strength of this study was that it was a prospective community-based cohort study which evaluated the association between $\mathrm{BP}$ and CKD across the range of BP.

However, there were also some limitations to this study. First, the study population consisted only of those aged 40-69 years. Nevertheless, our results may be representative of the general population in Korea because the data were from a community-based prospective cohort study, which may have minimized the sampling bias effect. Second, Scr and proteinuria were measured only once. According to the K/DOQI guidelines, CKD is defined as a GFR $<60 \mathrm{~mL} / \mathrm{min} / 1.73 \mathrm{~m}^{2}$ or kidney damage for at least three months; therefore, Scr and proteinuria should be evaluated more than once. Thus, there might be an underestimation or overestimation of the prevalence of CKD in both males and females. Third, the MDRD equation has not been validated in the Korean population. Therefore, eGFR calculation using the MDRD equation might be inaccurate. Fourth, each participant's BP measurement was based on only two readings of a single day. Also, we only evaluated in a state of BP control with BP values and selfreported medication at a baseline and 2-year follow-up. Therefore, the misclassification of BP may be possible and it might be underestimated or overestimated the prevalence of controlled BP and poorly-controlled BP.

\section{Conclusions}

Prehypertension, as well as hypertension, is significantly associated with CKD among middle-aged Koreans. Our results indicate that active control of the blood-pressure of prehypertensive individuals is necessary to prevent deterioration in kidney function. Therefore, we suggest that active blood-pressure control may play an important role in prevention of CKD.

\section{Additional files}

\section{Additional file 1: Mean GFR according to different estimating} equations.

Additional file 2: Prevalence of CKD according to the CKD-EPI equation.

Additional file 3: Prevalence of CKD according to the MDRD equation with the Korean coefficient.

Additional file 4: Prevalence of CKD according to the novel equation for Korean.

\footnotetext{
Abbreviations

BP: Blood Pressure; CKD: Chronic Kidney Disease; ESRD: End-Stage Renal Disease; CVD: CardioVascular Disease; KDOQI: Kidney Disease Outcomes Quality Initiative; eGFR: Estimated Glomerular Filtration Rate; Scr: Serum creatinine; KEEP: Kidney Early Evaluation Program; NHANES: National Health and Nutrition Examination Survey; BMI: Body Mass Index; WC: Waist Circumference; FPG: Fasting Plasma Glucose; TC: Total Cholesterol; TG: Triglyceride; HDL-C: High-Density Lipoprotein Cholesterol; LDL-C: LowDensity Lipoprotein Cholesterol; DM: Diabetes Mellitus; 2 h PG: 2-h Postchallenge plasma Glucose; $\mathrm{HbA}_{1}$ : Hemoglobin $\mathrm{A}_{1}$ c; $\mathrm{ADA}$ : American Diabetes
}

Association; ANOVA: One-way Analysis Of Variance; MDRD: Modification of Diet in Renal Disease; SBP: Systolic Blood Pressure; DBP: Diastolic Blood Pressure.

\section{Competing interests}

The authors declare that they have no competing interests.

\section{Authors' contributions}

MJK and HYP participated in the design of the study, performed the statistical analysis and participated in drafting the manuscript. NKL performed the statistical analysis. All authors read and approved the final manuscript.

\section{Acknowledgements}

This work was supported by a grant from the Korea National Institute of Health intramural research, No. 4800-4845-302-210 (2010-N63001-00).

Received: 15 February 2012 Accepted: 25 October 2012

Published: 9 November 2012

\section{References}

1. Weiner DE, Tighiouart H, Amin MG, Stark PC, MacLeod B, Griffith JL, Salem DN, Levey AS, Sarnak MJ: Chronic kidney disease as a risk factor for cardiovascular disease and all-cause mortality: a pooled analysis of community-based studies. J Am Soc Nephrol 2004, 15:1307-1315.

2. Shara NM, Resnick HE, Lu L, Xu J, Vupputuri S, Howard BV, Umans JG: Decreased gfr estimated by mdrd or cockcroft-gault equation predicts incident cvd: the strong heart study. J Nephrol 2009, 22:373-380

3. Wang F, Ye P, Luo L, Xiao W, Wu H: Association of risk factors for cardiovascular disease and glomerular filtration rate: a community-based study of 4,925 adults in Beijing. Nephrol Dial Transplant 2010, 25:3924-3931.

4. Nakamura K, Okamura T, Hayakawa T, Kadowaki T, Kita Y, Ohnishi $H$ Saitoh S, Sakata K, Okayama A, Ueshima H: Chronic kidney disease is a risk factor for cardiovascular death in a community-based population in japan: NIPPON DATA90. Circ J 2006, 70:954-959.

5. Kiyosue A, Hirata Y, Ando J, Fujita H, Morita T, Takahashi M, Nagata D, Kohro T, Imai Y, Nagai R: Relationship between renal dysfunction and severity of coronary artery disease in Japanese patients. Circ J 2010, 74:786-791

6. Coresh J, Selvin E, Stevens LA, Manzi J, Kusek JW, Eggers P, Van Lente F, Levey AS: Prevalence of chronic kidney disease in the United States. JAMA 2007, 298:2038-2047.

7. Kim S, Lim CS, Han DC, Kim GS, Chin HJ, Kim SJ, Cho WY, Kim YH, Kim YS: The prevalence of chronic kidney disease (CKD) and the associated factors to CKD in urban Korea: a population-based cross-sectional epidemiologic study. J Korean Med Sci 2009, 24(Suppl 1):S11-S21.

8. K/DOQI clinical practice guidelines for chronic kidney disease: Evaluation, classification, and stratification. Am J Kidney Dis 2002, 39(2 Suppl 1):S1-S266.

9. Levin A, Hemmelgarn B, Culleton B, Tobe S, McFarlane P, Ruzicka M, Burns K, Manns B, White C, Madore F, Moist L, Klarenbach S, Barrett B, Foley R, Jindal K, Senior P, Pannu N, Shurraw S, Akbari A, Cohn A, Reslerova M, Deved V, Mendelssohn D, Nesrallah G, Kappel J, Tonelli M: Guidelines for the management of chronic kidney disease. CMAJ 2008, 179:1154-1162.

10. Wühl E, Schaefer F: Medscape: managing kidney disease with blood-pressure control. Nat Rev Nephrol 2011, 7:434-444.

11. Udani S, Lazich I, Bakris GL: Epidemiology of hypertensive kidney disease. Nat Rev Nephrol 2011, 7:11-21.

12. Walker WG, Neaton JD, Cutler JA, Neuwirth R, Cohen JD: Renal function change in hypertensive members of the multiple risk factor intervention trial. Racial and treatment effects. The mrfit research group. JAMA 1992, 268:3085-3091.

13. Perneger TV, Nieto FJ, Whelton PK, Klag MJ, Comstock GW, Szklo M: A prospective study of blood pressure and serum creatinine. Results from the 'Clue' Study and the ARIC Study. JAMA 1993, 269:488-493.

14. Rao MV, Qiu Y, Wang C, Bakris G: Hypertension and CKD: Kidney Early Evaluation Program (KEEP) and National Health and Nutrition Examination Survey (NHANES), 1999-2004. Am J Kidney Dis 2008, 51(4 Suppl 2):S30-S37.

15. Chobanian AV, Bakris GL, Black HR, Cushman WC, Green LA, Izzo JL Jr, Jones DW, Materson BJ, Oparil S, Wright JT Jr, Roccella EJ: The Seventh 
Report of the Joint National Committee on Prevention, Detection, Evaluation, and Treatment of High Blood Pressure: the JNC 7 report. JAMA 2003, 289:2560-2572

16. Sabanayagam C, Shankar A, Lim SC, Tai ES, Wong TY: Hypertension, hypertension control, and chronic kidney disease in a Malay population in Singapore. Asia Pac J Public Health 2011, 23:936-945.

17. Higashikuni Y, Ishizaka N, Ishizaka Y, Toda E, Nagai R, Yamakado M: Relationship between blood pressure and chronic kidney disease in the Japanese population: the lower the better even in individuals without hypertension? Hypertens Res 2008, 31:213-219.

18. Shin C, Abbott RD, Lee H, Kim J, Kimm K: Prevalence and correlates of orthostatic hypotension in middle-aged men and women in Korea: the Korean Health and Genome Study. J Hum Hypertens 2004, 18:717-723.

19. Kim BG, Park JT, Ahn Y, Kimm K, Shin C: Geographical difference in the prevalence of isolated systolic hypertension in middle-aged men and women in Korea: the Korean Health and Genome Study. $J$ Hum Hypertens 2005, 19:877-883.

20. Friedewald WT, Levy RI, Fredrickson DS: Estimation of the concentration of low-density lipoprotein cholesterol in plasma, without use of the preparative ultracentrifuge. Clin Chem 1972, 18:499-502.

21. American Diabetes Association: Diagnosis and classification of diabetes mellitus. Diabetes Care 2010, 33(Suppl 1):S62-S69.

22. Jang SY, Kim IH, Ju EY, Ahn SJ, Kim DK, Lee SW: Chronic kidney disease and metabolic syndrome in a general Korean population: the Third Korea National Health and Nutrition Examination Survey (KNHANES III) Study. J Public Health 2010, 32:538-546.

23. Reyes D, Lew SQ, Kimmel PL: Gender differences in hypertension and kidney disease. Med Clin North Am 2005, 89:613-630.

24. Miller JA, Anacta LA, Cattran DC: Impact of gender on the renal response to angiotensin II. Kidney Int 1999, 55:278-285.

25. Chadban SJ, Briganti EM, Kerr PG, Dunstan DW, Welborn TA, Zimmet PZ, Atkins RC: Prevalence of kidney damage in Australian adults: The AusDiab kidney study. J Am Soc Nephrol 2003, 14(7 Suppl 2):S131-S138.

26. Zhang QL, Rothenbacher D: Prevalence of chronic kidney disease in population-based studies: systematic review. BMC Publ Health 2008, 8:117.

27. Imai E, Horio M, Iseki K, Yamagata K, Watanabe T, Hara S, Ura N, Kiyohara Y, Hirakata H, Moriyama T, Ando Y, Nitta K, Inaguma D, Narita I, Iso H, Wakai K, Yasuda Y, Tsukamoto Y, Ito S, Makino H, Hishida A, Matsuo S: Prevalence of chronic kidney disease (CKD) in the Japanese general population predicted by the MDRD equation modified by a Japanese coefficient. Clin Exp Nephrol 2007, 11:156-163.

28. $L i Z Y, X u G B$, Xia TA, Wang HY: Prevalence of chronic kidney disease in a middle and old-aged population of Beijing. Clin Chim Acta 2006, 366:209-215.

29. Crews DC, Plantinga LC, Miller ER 3rd, Saran R, Hedgeman E, Saydah SH, Williams DE, Powe NR: Prevalence of chronic kidney disease in persons with undiagnosed or prehypertension in the United States. Hypertension 2010, 55:1102-1109.

30. Levey AS, Stevens LA, Schmid CH, Zhang YL, Castro AF, Feldman HI, Kusek JW, Eggers P, Van Lente F, Greene T, Coresh J: A new equation to estimate glomerular filtration rate. Ann Intern Med 2009, 150:604-612.

31. Lee CS, Cha RH, Lim YH, Kim H, Song KH, Gu N, Yu KS, Lim CS, Han JS, Kim S, Kim YS: Ethnic coefficients for glomerular filtration rate estimation by the Modification of Diet in Renal Disease study equations in the Korean population. J Korean Med Sci 2010, 25:1616-1625.

32. Hsu CY, McCulloch CE, Darbinian J, Go AS, Iribarren C: Elevated blood pressure and risk of end-stage renal disease in subjects without baseline kidney disease. Arch Intern Med 2005, 165:923-928.

33. Klag MJ, Whelton PK, Randall BL, Neaton JD, Brancati FL, Ford CE, Shulman NB, Stamler J: Blood pressure and end-stage renal disease in men. $N$ Engl J Med 1996, 334:13-18

34. O'Seaghdha CM, Perkovic V, Lam TH, McGinn S, Barzi F, Gu DF, Cass A, Suh I, Muntner P, Giles GG, Ueshima H, Woodward M, Huxley R: Blood pressure is a major risk factor for renal death: an analysis of 560352 participants from the Asia-Pacific region. Hypertension 2009, 54:509-515.

35. Munkhaugen J, Lydersen S, Widerøe TE, Hallan S: Prehypertension, obesity, and risk of kidney disease: 20-year follow-up of the HUNT I study in Norway. Am J Kidney Dis 2009, 54:638-646.

36. Yano Y, Fujimoto S, Sato Y, Konta T, Iseki K, Moriyama T, Yamagata K, Tsuruya K, Yoshida H, Asahi K, Kurahashi I, Ohashi Y, Watanabe T:
Association between prehypertension and chronic kidney disease in the Japanese general population. Kidney Int 2012, 81:293-299.

37. Sarnak MJ, Greene T, Wang X, Beck G, Kusek JW, Collins AJ, Levey AS The effect of a lower target blood pressure on the progression of kidney disease: long-term follow-up of the modification of diet in renal disease study. Ann Intern Med 2005, 142:342-351.

38. Maki DD, Ma JZ, Louis TA, Kasiske BL: Long-term effects of antihypertensive agents on proteinuria and renal function. Arch Intern Med 1995, 155:1073-1080.

doi:10.1186/1471-2458-12-960

Cite this article as: Kim et al:: Relationship between prehypertension and chronic kidney disease in middle-aged people in Korea: the Korean genome and epidemiology study. BMC Public Health 2012 12:960.

\section{Submit your next manuscript to BioMed Central and take full advantage of:}

- Convenient online submission

- Thorough peer review

- No space constraints or color figure charges

- Immediate publication on acceptance

- Inclusion in PubMed, CAS, Scopus and Google Scholar

- Research which is freely available for redistribution 